\title{
Effects of ceramic primers and post-silanization heat treatment on bond strength of resin cement to lithium disilicate-based ceramic
}

\author{
Thaiane Rodrigues Aguiar ${ }^{1}$, Wladimir Franco de Sá Barbosa², Marina Di Francescantonio 3 \\ and Marcelo Giannini ${ }^{4^{*}}$
}

\section{*Correspondence:}

giannini@fop.unicamp.br

${ }^{4}$ Operative Dentistry

Division, Department

of Restorative Dentistry,

Piracicaba Dental School

State University of Campinas,

Av. Limeira, 901, Piracicaba,

SP Zip Code: 13414-903,

Brazil

Full list of author information is available at the end of the article

\begin{abstract}
This study evaluated the effect of different ceramic primers and heat treatment of silane coupling agents on bond strength of resin cement to glass ceramic. Five ceramic primers (Clearfil Ceramic Primer/CCP, MonoBond-S, ProSil, RelyX Ceramic Primer and Silano) and one conventional resin cement (RelyX ARC) were tested. Lithium disilicatebased ceramic plates were previously etched with hydrofluoric acid, except for CCP $(n=10)$. All silane agents were applied to ceramics according to the manufacturer's instructions and primed ceramics plates were heated (in oven at $100^{\circ} \mathrm{C}$ for $1 \mathrm{~min}$ ) or not before resin cement placement. Dual-cure resin cement was mixed and inserted in tubes $(0.75 \mathrm{~mm}$ diameter $\times 1 \mathrm{~mm}$ height) that were positioned over primed ceramic surfaces. Micro-shear testing was performed using a universal testing machine. Bond strength data were analyzed using two-way ANOVA and Tukey's test (5\%). Ceramic primer heating did not improve the bond strength of the resin cement to lithium disilicate. Most of ceramic primers did not indicate significant difference in bond strength among them; however, CCP yielded the lowest bond strength among the ceramic primers. In conclusion, when the silane was applied on etched surface the bond strength was higher and heat treatment of silane coupling agents did not affect the bond strength.
\end{abstract}

Keywords: Silane agent, Bond strength, Indirect restorations, Resin cement, Primer

\section{Background}

The silicon tetrahydride or silanes is an inorganic colourless gas with spontaneous combustion in air at room temperature [1-3]. Silane or functionalized silanes has widely industrial and medical applications, and works as coupling and impermeabilizing agent. Silane coupling agents have also been applied to bond glass and carbon fibers to polymer matrices, creating a strong adhesion of fibers and filler particles to the polymer matrix $[4,5]$.

In Dentistry, silane coupling agents is applied to bond filler particles to resin monomers of restorative composites and also to prepare all-ceramic restorations for adhesive cementation [6]. The superficial treatments of minerals and glass fillers become them more 
compatible and dispersible in the organic polymers. It improves the strength and wear of dental restorative composites [4]. Considering the dental ceramic materials, silane coupling agents or ceramic primers also provides stable and high bond strengths between the resin cement and ceramic, resulting in properly clinical longevity of indirect restoration [7-9].

The organofunctional alkoxysilane is the best-known coupling agents used for silanization of dental glass ceramics. This product is commercially available in two bottles or as a single solution, pre-hydrolyzed or no-mix ceramic primer in an alcohol or acetone solution. Silanes contain bifunctional monomers, which consist of a silanol group (or alkoxy group) that chemically reacts by covalent bonds formed through oxygen to the silicon atom to form a siloxane type of bond with hydroxyl groups from porcelain surface. The methacrylate group, an organic portion of the molecule, co-polymerizes with the resin matrix of the adhesive resin or resin cement [10].

The silanization process depends on various factors: type of organofunctional alkoxysilane; hydrolysis reaction; the removal of organic solvents and water. Water is the main product of condensation reaction between silane and ceramic [11], and the removal of both residual water and organic solvents is essential to improve the adhesion of resin cement to dental ceramics [12-15]. Curiously, manufacturers have suggested just air blowing after silane application, which apparently seems not enough to eliminate the residual water and organic solvents. To optimize the adhesion between lithium disilicate-based ceramic and resin cement, this study evaluated the influence of different silane coupling agents and post-silanization heat treatments. The null hypothesis tested was that heating treatment does not influence bond strengths to ceramic, regardless of the type of silane coupling agent.

\section{Methods}

One-hundred sintered plates (10 mm length $\times 5 \mathrm{~mm}$ wide $\times 1 \mathrm{~mm}$ thickness) of lithium disilicate-based ceramics (Ivoclar Vivadent, Schaan, Leichtenstein, Germany) were used in this study. The ceramic plates were randomly divided into ten experimental groups $(\mathrm{n}=10)$ according to the ceramic primer treatments (heating or none) and five commercial silane coupling agents (Clearfil Ceramic Primer, Kuraray Noritake Dental Inc., Kurashiki, Japan; RelyX Ceramic Primer, 3M ESPE, St. Paul, MN, USA; Monobond-S, Ivoclar Vivadent, Schaan, Liechtenstein; ProSil, FGM Prod. Odontol. Ltda, Joinville, SC, Brazil and Silano, Dentsply Brasil, Petrópolis, RJ, Brazil). Table 1 shows the composition and lot number of each ceramic primer used.

Ceramic plates were etched with 10\% hydrofluoric acid (FGM Prod. Odontol. Ltda, Joinville, SC, Brazil) for $20 \mathrm{~s}$, rinsed with water for $1 \mathrm{~min}$ and air-dried for $30 \mathrm{~s}$, except for Clearfil Ceramic Primer. All ceramic primers were applied according to the manufacturer's instructions. After priming, half of specimens were placed in an oven (FV Plus Sinter 50P, EDG Equipamentos Ltda, São Carlos, SP, Brazil) at $100{ }^{\circ} \mathrm{C}$ for $1 \mathrm{~min}$, while another half was kept at room temperature $\left(23^{\circ} \mathrm{C}\right)$.

Two cylindrical translucent molds (Tygon tubing, TYG-030, Saint-Gobain Performance Plastic, Maime Lakes, FL, USA) were positioned over the primed ceramic surfaces and freshly mixed dual-cured resin cement (RelyX CRA, 3M ESPE, St. Paul, MN, USA) was placed into the molds to fill their internal volume without loading on the resin cement-ceramic specimen. Resin cement was light activated $\left(550 \mathrm{~mW} / \mathrm{cm}^{2}\right)$ with $\mathrm{XL}$ 
Table 1 Composition and lot number of the materials used

\begin{tabular}{|c|c|c|}
\hline Materials used & Composition (lot number) & Application technique \\
\hline Clearfil Ceramic Primer & $\begin{array}{l}\text { Ethanol, 10-methacryloyloxydecyl dihy- } \\
\text { drogen phosphate, 3-methacryloyloxy- } \\
\text { propyl-trimethoxysilane (00002B) }\end{array}$ & $\begin{array}{l}\text { 1. Apply Clearfil Ceramic Primer } \\
\text { 2. Dry ceramic surface by blowing mild } \\
\text { oil-free air }\end{array}$ \\
\hline MonoBond-S & $\begin{array}{l}\text { Ethanol, water, 3-methacriloiloxipropil- } \\
\text { trimetoxisilane (K25651) }\end{array}$ & $\begin{array}{l}\text { 1. Apply Monobond-S with microbrush } \\
\text { 2. Allow the material to react for } 60 \mathrm{~s} \\
\text { 3. Disperse with a strong stream of air }\end{array}$ \\
\hline Prosil & $\begin{array}{l}\text { Ethanol, water, 3-methacryloyloxypropyl- } \\
\text { trimethoxysilane (250108) }\end{array}$ & $\begin{array}{l}\text { 1. Apply ProSil with microbrush } \\
\text { 2. Allow the material to react for } 60 \mathrm{~s} \\
\text { 3. Dry ceramic surface by blowing mild } \\
\text { oil-free air }\end{array}$ \\
\hline RelyX Ceramic Primer & $\begin{array}{l}\text { Ethanol, water, 3-methacryloxypropyl- } \\
\text { trimethoxysilane (7YF) }\end{array}$ & $\begin{array}{l}\text { 1. Apply RelyX Ceramic Primer to the inter- } \\
\text { nal (etched) surfaces } \\
\text { 2. Gently blow oil-free air across the } \\
\text { surface or allow the solvent to evaporate } \\
\text { completely }\end{array}$ \\
\hline Silano & Ethanol, glacial acetic acid, silane (769868) & $\begin{array}{l}\text { 1. Place one drop of Silane Primer and } \\
\text { Silane Activator into the mixing well } \\
\text { 2. Mix thoroughly for } 10-15 \mathrm{~min} \\
\text { 3. Leave the mixture for } 5 \mathrm{~min} \\
\text { 4. Apply Silane mixture and air-dry by } \\
\text { blowing } \\
\text { 5. Apply the second layer and air-dry by } \\
\text { blowing }\end{array}$ \\
\hline RelyX CRA & $\begin{array}{l}\text { BisGMA, TEGDMA, dimethacrylate } \\
\text { polymer, amine, photoinitiator system, } \\
\text { benzoyl peroxide, pigments, zirconia/ } \\
\text { silica fillers ( } 67.5 \% \text { by weight and } 1.5 \mu \mathrm{m} \\
\text { average particle size) (GEHG) }\end{array}$ & $\begin{array}{l}\text { 1. Dispense paste } A \text { and } B \text { of cement onto a } \\
\text { mixing pad and mix for } 10 \mathrm{~s} \\
\text { 2. Light cured for } 40 \mathrm{~s}\end{array}$ \\
\hline
\end{tabular}

3000 curing unit (3M ESPE, St. Paul, MN, USA) for $40 \mathrm{~s}$, as recommended by the manufacturer. The micro-shear test used in this study followed the methodology developed by Shimada et al. [16].

Ceramic plates were stored in distilled water at $37{ }^{\circ} \mathrm{C}$ for $24 \mathrm{~h}$ and then tube molds were removed with a surgical blade (\#11, All Pro Surgical Blade Co., Qingdao, China) to expose the resin cement cylinders $(0.75 \mathrm{~mm}$ diameter by $0.5 \mathrm{~mm}$ high). All resin cylinders were checked under a stereo microscope (30X, EMZ-TR, Meiji Techno Co., LTD., Saitama, Japan) to excluded resin cylinders with defects at the bonding interface. Each ceramic plate was attached to the testing device with cyanoacrylate adhesive (Super Bonder, Loctite, Itapevi, SP, Brazil) and tested in a universal testing machine (4411, Instron Corp., Canton, MA, USA). A shear load was applied to the base of the resin cement cylinder with a thin wire $(0.20 \mathrm{~mm}$ diameter $)$ at a crosshead speed of $0.5 \mathrm{~mm} /$ min until failure. The shear bond strengths were calculated (kgf obtained for each speci$\left.\mathrm{men} / 1.32 \mathrm{~mm}^{2}\right)$ and expressed in $\mathrm{MPa}\left(\mathrm{N} / \mathrm{m}^{2}\right)$. The bond strength value for each plate was presented by the mean of the two resin cement cylinders of each plate. The exploratory analysis of the data was performed using the PROC LAB procedure of the SAS statistical program (version 9.1, SAS Institute, Cary, NC, USA), and demonstrated that they fulfilled the assumptions of a parametric analysis. The results were analyzed by 2-way ANOVA (treatment X ceramic primers) and Tukey's test (5\% level of significance).

After testing, the debonded ceramic plates were mounted on aluminum stubs, gold/ palladium sputter coated (SCD 050, Baltec, Vaduz, Liechtenstein) and observed under 
high vacuum by scanning electron microscopy (SEM) (VP-435, Leo, Cambridge, United Kingdom). Failure patterns were classified as: (1) cohesive failure within resin cement and (2) mixed fracture, which involved adhesive failure and cohesive fracture within resin cement. Photomicrographs of representative areas of the fractured surfaces were taken at $100 \times$ magnification.

\section{Results}

Two-way ANOVA indicated that the factor "ceramic primer" $(\mathrm{p}<0.00001)$ significantly affected the bond strength results. The "treatment" factor $(\mathrm{p}=0.1459)$ and the interaction factor $(\mathrm{p}=0.3676)$ were not significant. Table 2 displays a summary of the statistics for the different experimental groups. The heat treatment of ceramic primer did not increase the bond strength of resin cement to lithium disilicate-based ceramic $(p<0.05)$. The Clearfil Ceramic Primer presented the lowest bond strength among silane coupling agents $(p>0.05)$.

Representative images of failure modes are shown in Figs. 1 and 2. Few mixed fractures were observed for some ceramic primers (Fig. 1), while no adhesive failures along the ceramic surface were observed for ceramic primers regardless on the heat treatment. Cohesive failure within resin cement was the most predominant pattern for all groups (Fig. 2). Overall, heat treatment did not influence the failure pattern.

Table 2 Summary statistics [mean (sd)] of microshear bond strength (MPa) among experimental groups $(\mathbf{n}=10)$

\begin{tabular}{lll}
\hline Silane coupling agent & \multicolumn{2}{l}{ Treatment } \\
\cline { 2 - 3 } & Heating & None \\
\hline Clearfil Ceramic Primer & $37.4 \pm 8.0 \mathrm{Ab}$ & $31.8 \pm 7.3 \mathrm{Ab}$ \\
MonoBond-S & $48.7 \pm 5.5 \mathrm{Aa}$ & $48.4 \pm 3.9 \mathrm{Aa}$ \\
ProSil & $43.1 \pm 7.4 \mathrm{Aa}$ & $44.9 \pm 6.9 \mathrm{Aa}$ \\
RelyX Ceramic Primer & $46.8 \pm 4.2 \mathrm{Aa}$ & $43.6 \pm 5.1 \mathrm{Aa}$ \\
Silano & $45.2 \pm 3.3 \mathrm{Aa}$ & $43.6 \pm 6.9 \mathrm{Aa}$ \\
\hline
\end{tabular}

Values of groups having similar letters were not significantly different $(p=0.05)$. (uppercase letters $=$ rows; lowercase letters $=$ column)

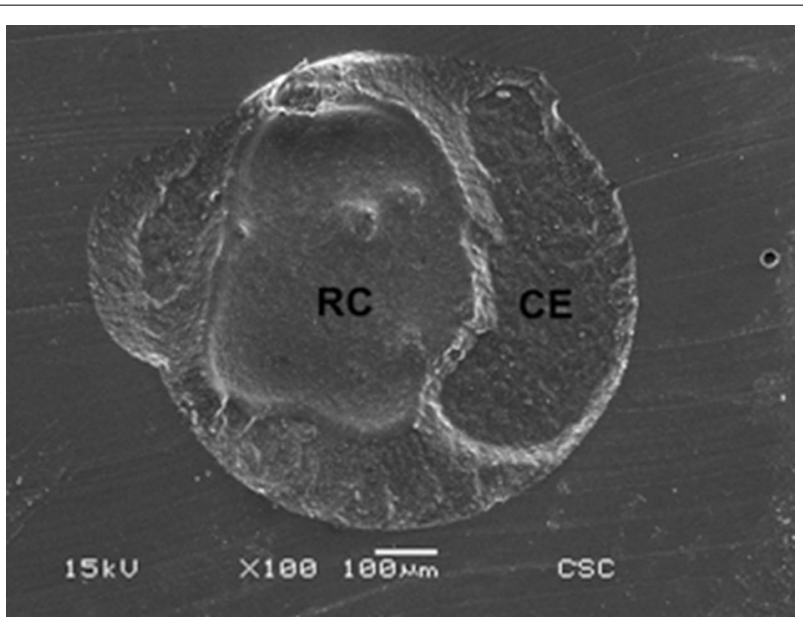

Fig. 1 Mixed fracture involving cohesive failure of resin cement and adhesive failure obtained for non-heated Clearfil Ceramic Primer (RC resin cement, CE ceramic) (magnification $\times 100$ ) 


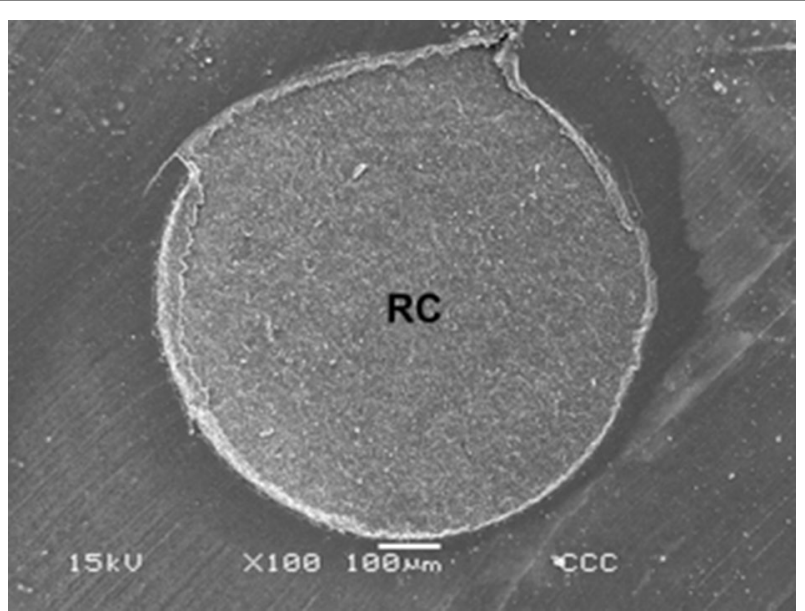

Fig. 2 Cohesive failure within resin cement (RC) obtained for heated Clearfil Ceramic Primer (magnification $\times 100)$

\section{Discussion}

The post-silanization heat treatment tested in this study did not increase the bond strength. However, studies showed an increase in bond strength using heated air from air dryer. It seems to be more efficient technique to remove the water from condensation reaction and the other organic solvents present in the composition of silane coupling agents [12, 17-20]. Thus, the null hypothesis that oven heating treatment does not influence bond strengths to ceramic, regardless of the type of silane coupling agent used was accepted.

Although some authors have suggested the use of heated air-dryer, no standard technique has been preconized regarding temperature, air flux, type of heated air and distance from the air-dryer, as well as other methods. Sadoun and Asmussen [17] used air dryer at $95{ }^{\circ} \mathrm{C}$ for $2 \mathrm{~min}$, while Roulet et al. [18] tested a gun of heated air at $100{ }^{\circ} \mathrm{C}$ for $1 \mathrm{~min}$. Shen et al. [19] suggested stream of warm air for 2 min at $45^{\circ} \mathrm{C}$, while Abduljabbar et al. [12] and Hooshmand et al. [20] used an oven at $100^{\circ} \mathrm{C}$ for 5 and 2 min, respectively, and both types of heating treatment enhance the bond strength.

Most of studies have shown that heating silane improve the bond strength of resin cements to ceramics. De Carvalho et al. [21] heated a pre-hydrolyzed silane containing MDP (Clearfil Ceramic Primer) in an oven at $100{ }^{\circ} \mathrm{C}$ for $2 \mathrm{~min}$ or applied hot air at $50{ }^{\circ} \mathrm{C}$ for $1 \mathrm{~min}$. The results of that study indicated that both treatments were effective in increasing the bond strength values between the feldspathic ceramic and resin cement. Corazza et al. [15], used five strategies to treat the ceramic surface, which involved a control group (only etching with hydrofluoric acid $10 \%$ and silanization at room temperature) and experimental groups involving oven drying of silane at $77^{\circ} \mathrm{C}$ and hot water rinsing. Oven drying improved the bond strength between the resin cement and feldspathic ceramic, but hot water rinsing reduced the bond strength. Another investigation that performed the silane heating in an oven at $100{ }^{\circ} \mathrm{C}$ for 2 min instead of hydrofluoric acid etching showed that heated silane alone did not increase the bond strength [14]. When compared with the current study, it seems that both the heat treatment and the ceramic type may influence the bond strength results. 
As used herein, lithium disilicate-based ceramics plates were placed in an oven for $1 \mathrm{~min}$ at $100{ }^{\circ} \mathrm{C}$. The results showed no significant difference regarding the groups that were kept at room temperature $\left(23^{\circ} \mathrm{C}\right)$. The placement of plates inside the oven did not allow air flux in the direction of ceramic plates, the gun of heated air or heated air flux may be the best option to allow air flux, because they permit the movement the air that removes water and organic solvents better than static air. Thus, the lack of heated airdrying movement may explain the differences found between post-silanization heat strategies.

Although silanes used in this study were applied differently, few statistical differences were found among silanes. These materials present similar compositions and are prehydrolyzed primers, except Silano (Dentsply Brasil). The lowest bond strength was found for a pre-hydrolyzed silane containing phosphate monomer-based MDP. Its manufacturer does not recommend hydrofluoric acid etching, because MDP monomer should be able bond to ceramic without acid etching treatment by very strong bonds to $\mathrm{SiO}_{2}$ based ceramics and metal oxides [21]. Without the microporosities promoted by acid etching, the silane containing phosphate monomer-based MDP yielded approximately 19\% (for heat treatment) and 29\% (no heating) lower bond strength than those silanes applied to acid etched ceramic.

The acid etching may be important to improve bond strength results of Clearfil Ceramic Primer to glass ceramics, not because creates a highly porous surface, but also highly receptive to the silane by forming reactive hydroxyl groups on the ceramic surface. Studies have shown that the combination between silane and acidic functional monomers accelerate the hydrolyze reaction of alkoxy groups in silanol, increasing the reactivity of silanes [16-22].

The failure pattern demonstrated predominance of cohesive failure within resin cement for all silanes tested regardless of the heating treatment. Because the failure pattern was similar among groups, these results help to explain the bond strength data, which detected little differences among silanes. A study in which premature failures were considered, furnace heat treatment delivered the second best results after the control group, being considerably better than hot air application and not using acid etching [23]. The harmful aspects of insufficiently solvent evaporation on the bond strength were the objectives of this short-term study. It is known in the literature that long-term degradation process reduces bond strength of resin cement to glass ceramics, consequently increasing the adhesive failure [24, 25]. Therefore, the long-term evaluations will the target of future studies in this research line, because the aging of specimens might find different results with significant statistically difference among groups.

\section{Conclusions}

The heat treatment of silane did not improve the bond strength of resin cement to lithium disilicate-based ceramic, however, further studies must evaluate the effects of post-silanization heat treatments of silanized ceramics on long-term to consider this treatment as essential strategy to obtain longevity of indirect restoration. 


\begin{abstract}
Author details
${ }_{1}^{1}$ Department of Clinical Dentistry, Federal University of Bahia, Salvador, BA, Brazil. ${ }^{2}$ Department of Dentistry, School of Health Sciences, State University of Amazonas, Manaus, AM, Brazil. ${ }^{3}$ Department of Restorative Dentistry, Piracicaba Dental School, State University of Campinas, Piracicaba, SP, Brazil. ${ }^{4}$ Operative Dentistry Division, Department of Restorative Dentistry, Piracicaba Dental School, State University of Campinas, Av. Limeira, 901, Piracicaba, SP Zip Code: 13414-903, Brazil.
\end{abstract}

\title{
Acknowledgements
}

This study was supported by FAPEAM and CNPq (307217-2014-0).

\section{Competing interests}

There are non-financial competing interests (political, personal, religious, ideological, academic, intellectual, commercial or any other) to declare in relation to this manuscript.

Received: 15 October 2016 Accepted: 1 December 2016

Published online: 07 December 2016

\section{References}

1. Kondo S, Tokuhashi K, Nagai H, Iwasaka M, Kaise M. Spontaneous ignition limits of silane and phosphine. Combust Flame. 1995;101:170-4.

2. Chen JR, Tsai HY, Chen SK, Pan HR, Hu SC, Shen CC, Kuan CM, Lee YC, Wu CC. Analysis of a silane explosion in a photovoltaic fabrication plant. Process Saf Prog. 2006;25:237-44.

3. Chang YY, Peng DJ, Wu HC, Tsaur CC, Shen CC, Tsai HY, Chen JR. Revisiting of a silane explosion in a photovoltaic fabrication plant. Process Saf Prog. 2007;26:155-8.

4. Cramer NB, Stansbury JW, Bowman CN. Recent advances and developments in composite dental restorative materials. J Dent Res. 2011;90:402-16.

5. Moriguchi K, Utagawa S. Silane: chemistry, applications and performance. New York: Nova Science Publishers; 2012.

6. Lung CY, Matinlinna JP. Aspects of silane coupling agents and surface conditioning in dentistry: an overview. Dent Mater. 2012;28:467-77.

7. Matinlinna JP, Lassila LV, Vallittu PK. The effect of five silane coupling agents on the bond strength of a luting cement to a silica-coated titanium. Dent Mater. 2007;23:1173-80.

8. Matinlinna J, Ozcan M, Lassila L, Kalk W, Vallittu P. Effect of the cross-linking silane concentration in a novel silane system on bonding resin-composite cement. Acta Odontol Scand. 2008;66:250-5

9. Bertolotti RL. Adhesion to porcelain and metal. Dent Clin N Am. 2007;51:433-51.

10. Thames SM, Panjnani KG. Organosilane polymer chemistry: a review. J Inorg Organomet Polym. 1996;6:59-94.

11. Witucki G. A silane primer: chemistry and applications of alkoxy silanes. J Coat Technol. 1993;65:57-60.

12. Abduljabbar T, Al Qahtani MA, Jeaidi ZA, Vohra F. Influence of silane and heated silane on the bond strength of lithium disilicate ceramics_-an in vitro study. Pak J Med Sci. 2016;32:550-4.

13. Magne P, Belser U. Bonded porcelain restorations in the anterior dentition: a biomimetic approach. Hanover Park: Quintessence Publishing Co Inc.; 2002.

14. de Carvalho RF, Martins ME, de Queiroz JR, Leite FP, Ozcan M. Influence of silane heat treatment on bond strength of resin cement to a feldspathic ceramic. Dent Mater J. 2011;30:392-7.

15. Corazza PH, Cavalcanti SC, Queiroz JR, Bottino MA, Valandro LF. Effect of post-silanization heat treatments of silanized feldspathic ceramic on adhesion to resin cement. J Adhes Dent. 2013;15:473-9.

16. Shimada Y, Yamaguchi S, Tagami J. Micro-shear bond strength of dual-cured resin cement to glass ceramics. Dent Mater. 2002;8:380-8.

17. Sadoun M, Asmussen E. Bonding of resin cements to an aluminous ceramic: a new surface treatment. Dent Mater 1994;10:185-9.

18. Roulet JF, Söderholm KJ, Longmate J. Effects of treatment and storage conditions on ceramic/composite bond strength. J Dent Res. 1995;74:381-7.

19. Shen C, Oh WS, Williams JR. Effect of post-silanization drying on the bond strength of composite to ceramic. J Prosthet Dent. 2004;91:453-8.

20. Hooshmand T, van Noort R, Keshvad A. Bond durability of the resin-bonded and silane treated ceramic surface. Dent Mater. 2002;18:179-88.

21. de Carvalho RF, Cotes C, Kimpara ET, Leite FP, Özcan M. Heat treatment of pre-hydrolyzed silane increases adhesion of phosphate monomer-based resin cement to glass ceramic. Braz Dent J. 2015;26:44-9.

22. Papacchini F, Toledano M, Monticelli F, Osorio R, Radovic I, Polimeni A, Garcia-Godoy F, Ferrari M. Hydrolytic stability of composite repair bond. Eur J Oral Sci. 2007;115:417-24.

23. Cotes C, de Carvalho RF, Kimpara ET, Leite FP, Ozcan M. Can heat treatment procedures of pre-hydrolyzed silane replace hydrofluoric acid in the adhesion of resin cement to feldspathic ceramic? J Adhes Dent. 2013;15:569-74.

24. Liu Q, Meng X, Yoshida K, Luo X. Bond degradation behavior of self-adhesive cement and conventional resin cements bonded to silanized ceramic. J Prosthet Dent. 2011;105:177-84.

25. Meng XF, Yoshida K, Gu N. Chemical adhesion rather than mechanical retention enhances resin bond durability of a dental glass-ceramic with leucite crystallites. Biomed Mater. 2010;5:044101. 